\section{O PRINCÍPIO DA DIGNIDADE DA PESSOA HUMANA E O DIREITO À EDUCAÇÃO: UMA ANÁLISE SOB A ÓTICA DA SOCIEDADE DE RISCO}

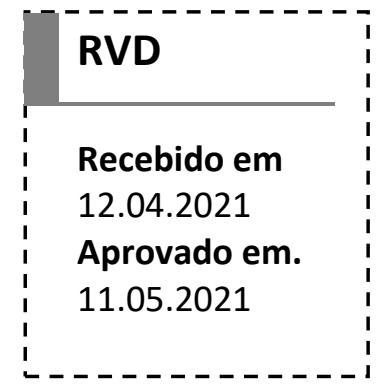

\author{
THE DIGNITY PRINCIPLE OF THE HUMAN PERSON AND \\ THE RIGHT TO EDUCATION: AN ANALYSIS FROM THE \\ RISK SOCIETY VIEW
}

Wellington Gustavo Pereira ${ }^{1}$

Gabrielle Valeri Soares ${ }^{2}$

\title{
RESUMO
}

Este estudo analisa os desafios que a observância prática do princípio da dignidade da pessoa humana encontra na sociedade de risco de Ulrich Beck, bem como a necessidade do surgimento de uma nova ética capaz de balizar as ações humanas, cujas consequências extrapolam as noções usuais e simultâneas de tempo e espaço. $\mathrm{Na}$ forma de um exemplo sintético, pretende-se pensar o Direito à Educação em face da teoria de Beck, com diálogos com Hannah Arendt e José Sérgio Fonseca de Carvalho. Ademais, a presente pesquisa verifica que a efetividade dos direitos humanos está sujeita a diversos obstáculos, tais como: a ausência de tutela internacional efetiva, a presença de critérios vagos para a resolução de conflitos entre os direitos fundamentais relativos e a necessidade de especificação dos direitos humanos já existentes. A metodologia utilizada compreende uma abordagem qualitativa, dialética, de natureza básica, contendo um objetivo explicativo e um procedimento bibliográfico, documental,

\footnotetext{
1 Doutor em Educação pela Universidade de São Paulo. Mestre em Teoria Literária e Literatura Comparada pela Universidade de São Paulo. Graduado em Letras pela Universidade de São Paulo. Professor da rede municipal de educação do munícipio de São Paulo. E-mail: wellgus23@gmail.com. ORCID: https://orcid.org/0000-0003-4780-7410. Endereço: Rua Guarantã, S/N, CEP: 03924-120, Parque dos Bancários, São Paulo - SP.

2 Mestranda em Filosofia do Direito na Pontifícia Universidade Católica de São Paulo (PUCSP). Especialista em Direito Civil e Empresarial e em Direito e Processo do Trabalho pela Faculdade de Direito Professor Damásio de Jesus. Graduada em Direito pela Fundação Armando Álvares Penteado Advogada. E-mail: gabriellevaleriadv@gmail.com. ORCID: https://orcid.org/0000-0003-4956-1805. Endereço: Alameda Terracota, n. 215, Cj 518 e 519, sala 139, CEP: 09531-190, Bairro Cerâmica, São Caetano do Sul - SP.
} 
histórico e observacional. Os resultados da pesquisa realizada apontam que a problemática erigida somente pode ser solucionada mediante uma resposta transdisciplinar, amparada pelo paradigma da complexidade de Edgar Morin, além de frisar a necessidade de uma maior participação dos Estados em organizações internacionais. Por fim, a pesquisa também apontou que os critérios construídos pelo neoconstitucionalismo podem servir de base para o deslinde de eventuais choques entre os direitos fundamentais relativos.

PALAVRAS-CHAVE: Sociedade de risco. Ética. Dignidade da pessoa humana. Direitos humanos. Transdisciplinaridade.

\section{ABSTRACT}

This study analyses the practical challenges that the principle of the dignity of the human person encounters in Ulrich Beck's risk society, as well as the need for the emergence of a new ethics capable of directing human actions which consequences extrapolate the usual and simultaneous notions of time and space. In the form of a synthetic example, we intend to think about the Right to Education in the face of Beck's theory, with dialogues with Hannah Arendt and José Sérgio Fonseca de Carvalho. Moreover, this research verifies that the effectiveness of human rights is subject to several obstacles, such as: the absence of effective international protection, the presence of vague criteria regarding the conflict resolution between non absolute fundamental rights and the need of specification of existing human rights. The methodology used has a basic nature, comprehending a qualitative and dialectical approach, with explanatory purpose and bibliographic, documental, historical and observational procedure. The research result shows that the addressed issue can only be solved by a transdisciplinary response, supported by Edgar Morin's complexity paradigm, besides highlighting the need for a greater participation of States in international organizations. Lastly, the research also pointed that the criteria built by neoconstitucionalism can serve as a bases for the resolution regarding conflicts between non-absolute fundamental rights.

KEYWORDS: Risk society. Ethics. Dignity of the human person. Human rights. Transdisciplinarity. 
DOI 10.20873/uft.2359-0106.2021.v8n2.p86-115

\section{INTRODUÇÃO}

A expressão "pós-modernidade" é polêmica e a literatura a respeito do tema, apesar de vasta, é divergente no que tange às análises feitas sobre o contexto histórico, social e cultural que se iniciou ao final século XX (ainda que não haja concordância a respeito do marco inicial do referido período) e que possui, como características principais, a superação dos paradigmas construídos durante a modernidade e a incapacidade de gerar consenso.

Barroso explica que o conceito de pós-modernidade compreende uma combinação de "estilos, a descrença do poder absoluto da razão, o desprestígio do Estado. A era da velocidade. A imagem acima do conteúdo. O efêmero e o volátil parecem derrotar o permanente e o essencial." (2001, p. 10).

Com efeito, talvez a ausência de certezas seja uma consequência do fato de que a modernidade não deixou simplesmente de existir. Os paradigmas, as instituições e os valores da modernidade ainda estão em voga, ao mesmo tempo em que o que se denomina "pós-modernidade" começa a instalar-se de maneira paulatina. A pósmodernidade, neste sentido, não é o produto de valores homogêneos ou unitários, mas é, na verdade:

[...] uma força subterrânea a irromper na superfície somente para mostrar seu vigor, aqui e ali, trazendo instabilidade, erosões e erupções, sentidas como abalos da segurança territorial na qual se encontravam anteriormente instaladas as estruturas valorativas e as vigas conceptuais da modernidade. (BITTAR, 2008, p. 135).

É possível analisar, ainda que de forma perfunctória, o contexto geral do que usualmente se denomina "pós-modernidade". O Estado soberano clássico, conforme bem observa Barroso, deixou de ser o guardião da justiça e do progresso social. Hodiernamente, o Estado é visto como um protetor do lucro e da competitividade; além disso, a noção tradicional de soberania também perdeu força diante dos blocos 
econômicos e políticos que fortalecem a livre circulação de bens e de pessoas. (2001, p. 11).

A pós-modernidade trouxe, conforme já explicitado, uma mudança de paradigma. O choque cultural entre a modernidade e a pós-modernidade impactou 0 universo jurídico, visto que o Direito está situado no centro das questões culturais. De fato, se a consolidação de determinados valores majoritários é necessária para a aplicação e formulação do Direito, surge a pergunta: que tipo de consenso um mundo em transformação e em transição poderia alcançar? (BITTAR, 2008, p. 135).

A partir deste contexto, pretende-se analisar o que Ulrich Beck denomina "sociedade de risco", bem como as mudanças que esta nova configuração social, política, econômica e cultural trouxe para o universo da ética e, consequentemente, para a aplicação prática do princípio da dignidade da pessoa humana. Também se pretende analisar as dificuldades atinentes à efetivação prática dos direitos, imprescindíveis para a concretização da dignidade da pessoa humana, em especial, o direito à educação, sobre o qual, inicialmente, não parecem existir controvérsias.

A metodologia utilizada compreende uma abordagem qualitativa, dialética, de natureza básica, contendo um objetivo explicativo e um procedimento bibliográfico, documental, histórico e observacional.

A segunda seção abordará a ideia de sociedade de risco construída por Ulrich Beck e as respectivas observações conexas realizadas pelo entomologista Edward Wilson e pela bióloga Rachel Carson. A terceira seção, por sua vez, tratará da questão concernente ao vazio ético identificado por Zygmunt Bauman e por Jacques Ellul, sem deixar de ressaltar a proposta de uma nova ética sugerida por Hans Jonas.

No quarto segmento, como exemplo analítico sintético, tem-se um olhar voltado para o direito à educação, com contribuições de Hannah Arendt e José Sérgio Fonseca de Carvalho. Por fim, a quinta seção irá identificar, sob a ótica de Norberto Bobbio, as dificuldades que a efetivação dos direitos humanos enfrenta na atualidade, além de pontuar como a problemática erigida relaciona-se com o paradigma da complexidade de Edgar Morin. 
DOI 10.20873/uft.2359-0106.2021.v8n2.p86-115

\section{A SOCIEDADE DE RISCO}

O sociólogo alemão Ulrich Beck, em sua obra intitulada "Sociedade de Risco: rumo a uma outra modernidade", empreende a tarefa de "compreender os conteúdos que o desenvolvimento histórico da modernidade nas últimas duas, três décadas, especialmente na Alemanha Ocidental", conferiu à partícula "pós" da sentença "pósmodernidade". (2010, p. 7).

Neste sentido, Beck entrevê a existência de duas fases no processo de modernização: a primeira fase corresponde a uma modernização que teria ocorrido "nos trilhos da sociedade industrial'; ao passo que a segunda fase se traduz em uma modernização das "premissas da sociedade industrial". (2010, p. 13):

[...] A modernização consumiu e perdeu seu contrário, encontrando afinal a si mesma em meio a premissas e princípios funcionais socioindustriais. Se no século XIX foram os privilégios estamentais e as imagens religiosas do mundo que passaram por um desencantamento, hoje é o entendimento científico e tecnológico da sociedade industrial clássica que passa pelo mesmo processo as formas de vida e de trabalho na família nuclear e na profissão, os papéismodelo de homens e mulheres, etc. (BECK, 2010, p.13).

O sociólogo explica que, na sociedade industrial, a lógica da produção de riquezas tinha o condão de dominar a lógica da produção de riscos, mas que, na sociedade industrial de risco a relação inverte-se, de sorte que a produção de riscos ofusca cada vez mais o progresso tecnológico-econômico. (BECK, 2010, p.15).

Os riscos e os efeitos decorrentes da segunda fase da modernidade consubstanciam-se em ameaças à vida de plantas, animais e seres humanos, ameaças estas de natureza global, supranacional e independentes de classe. (BECK, 2010, p. 16).

Ulrich Beck explica que a produção de riquezas apresenta o efeito colateral de produzir riscos, riscos estes que extrapolam o usual funcionamento da sociedade de 
classes, na mesma medida em que aprofundam as desigualdades que dela decorrem. É o que se depreende do seguinte excerto:

$\mathrm{Na}$ modernidade tardia, a produção social de riqueza é acompanhada sistematicamente pela produção social de riscos. Consequentemente, aos problemas e conflitos distributivos da sociedade da escassez sobrepõem-se os problemas e conflitos surgidos a partir da produção, definição e distribuição de riscos científico-tecnologicamente produzidos. (BECK, 2010, p. 23).

Desta configuração, Beck constrói cinco teses capazes de explicitar como funcionam as dinâmicas política e social da sociedade de risco. Na primeira tese os riscos são diferentes das riquezas; os riscos causariam danos irreversíveis, por vezes invisíveis, baseando-se em interpretações causais, porquanto somente se apresentam quando deles têm-se o conhecimento, além de estarem abertos a processos sociais de definição. (2010, p. 27).

$\mathrm{Na}$ segunda tese apresentada os riscos implodem o esquema de classes, na medida em que acabam atingindo os agentes que os produziram ou que com eles lucraram. (BECK, 2010, p. 27). Na terceira tese, o autor traz a ideia de que os riscos são um grande negócio, vez que "a fome pode ser saciada, necessidades podem ser satisfeitas, mas os riscos civilizatórios são um barril de necessidades sem fundo, interminável, infinito, auto produzível." (BECK, 2010, p. 28). Assim, os riscos podem ser objetos de lucro e de exploração econômica.

A quarta tese de Beck abarca a noção de que as riquezas podem ser possuídas, ao passo que os riscos somente podem ser atribuídos ou "sofridos". O sociólogo explica que "em situações relativas à classe ou camada social, a consciência é determinada pela existência, enquanto, nas situações de ameaça, é a consciência que determina a existência. O conhecimento adquire uma nova relevância política." (2010, p. 28). Por fim, a quinta tese consiste na percepção de que os efeitos sociais e econômicos causados pelos riscos tornam-se políticos:

Riscos socialmente reconhecidos, da maneira como emergem claramente, pela primeira vez, no exemplo das discussões em torno do desmatamento, contêm um peculiar ingrediente político explosivo: aquilo que até há pouco era tido por 
DOI 10.20873/uft.2359-0106.2021.v8n2.p86-115

apolítico torna-se político - o combate às 'causas' no próprio processo de industrialização. (BECK, 2010, p. 28).

O que se pode depreender do contexto traçado por Beck é que a produção de riquezas (bens e serviços) gera riscos, riscos estes que aparecem, por exemplo, na disseminação de toxinas no meio ambiente; entretanto, é importante dizer que Ulrich Beck esclarece no livro em comento que a discussão erigida acerca dos poluentes ainda é muito restrita ao âmbito das ciências naturais, não sendo objeto de inquirições os seus sentidos social e cultural.

Ademais, Beck ressalta que "enquanto renda, educação etc. forem para o indivíduo bens consumíveis, tangíveis, a existência e a distribuição de ameaças e riscos serão medidas de modo invariavelmente argumentativo.” (2010, p. 32).

A imprevisibilidade e, por vezes, a invisibilidade dos riscos constroem uma conjuntura em que os seres humanos têm a sua confiança violada, a sua certeza perdida, o que implica no surgimento de interrogações a respeito da aceitação humana perante este panorama:

Por trás de todas as reificações, cedo ou tarde emerge a questão da aceitação e, com ela, a velha nova questão: como queremos viver? O que há de humano no ser humano, de natural na natureza, que é preciso proteger? Nesse sentido, o propalado discurso da 'catástrofe' é a expressão exagerada, radicalizada, objetivante de que tal processo não é desejado (BECK, 2010, p. 34).

A observação feita por Beck pode ser relacionada à reflexão formulada por Edward Wilson em sua obra intitulada "Diversidade da Vida". Primeiramente, cumpre ressaltar que Wilson é um entomologista e biólogo americano que tece considerações concernentes à importância da biodiversidade, conforme demonstrado nos seguintes excertos:

Por que deveríamos nos importar com isso? Que diferença faz se algumas espécies são extintas, se até mesmo metade das espécies da Terra desaparecerem? Enumeremos os motivos. Novas fontes de informação se perderão. Uma enorme riqueza biológica potencial será destruída. Medicamentos, produtos agrícolas, produtos farmacêuticos, madeiras, fibras, 
polpas, vegetação restauradora do solo, substitutos do petróleo e outros recursos e confortos jamais virão à tona. [...]. Desconsiderar a diversidade da vida é correr o risco de nos lançarmos em um ambiente estranho e hostil. (2012, p. 372/373).

Entretanto, Edward Wilson defende que uma ética ambiental durável não pode ter por fundamento somente os motivos supracitados, posto que "se é possível colocar um preço em algo, este algo pode ser desvalorizado, vendido e descartado" (2012, p. 373). Assim, a biodiversidade não deveria ser somente objeto de preservação pelo motivo de poder trazer benefícios de ordem econômica e financeira ao ser humano (medicamentos, produtos agrícolas e farmacêuticos, substitutos do petróleo, etc.).

Wilson explica que a humanidade é parte da natureza, constituindo uma espécie que evoluiu ao lado de outras espécies, de maneira que, quanto mais os seres humanos identificarem-se com o restante da vida, "mais rapidamente seremos capazes de descobrir as origens da sensibilidade humana e de que adquirir o conhecimento sobre o qual fundamentar uma ética durável" (2012, p. 374).

Com efeito, o entomologista deixa claro que o convívio do ser humano com outras formas de vida é importante não somente para o corpo, mas também para 0 espírito humano. A título exemplificativo, Wilson expõe retratos do que ele denomina biofilia (ligações que os seres humanos buscam subconscientemente com o restante da vida):

Somente nestes últimos momentos da história humana é que surgiu a ilusão de que as pessoas podem florescer separadas do resto do mundo vivente. Sociedades pré-letradas mantinham íntimo contato com uma gama espantosa de formas de vida. Suas mentes só podiam se adaptar em parte a tamanho desafio, mas esforçavam-se para compreender os aspectos mais relevantes, cientes de que as respostas corretas produziam vida e plenitude, e as erradas, doença, fome e morte. As marcas desse esforço não poderiam ter sido apagadas em algumas poucas gerações da existência urbana e sugiro que elas podem ser encontradas entre as particularidades da natureza humana [...] (2012, p. 374).

Nesta perspectiva, é imprescindível que os seguintes aspectos sejam sublinhados: (a) - os riscos causados pela produção das riquezas trazem consigo impactos ambientais; (b) - os impactos ambientais ocasionados pelos riscos importam 
DOI 10.20873/uft.2359-0106.2021.v8n2.p86-115

em prejuízo à biodiversidade e, consequentemente, à vida humana, inclusive sob o aspecto mental/psicológico; (c) - apesar da produção de riscos não obedecer à lógica da sociedade de classes, é verdade que agentes que possuem melhores condições financeiras logram proteger-se dos mencionados impactos de forma mais efetiva do que os agentes que não são tão abastados;

Por conseguinte, é importante questionar até que ponto está comprometida, até mesmo de maneira irreversível, a dignidade da pessoa humana sob esta perspectiva. Rachel Carson, na obra intitulada "Primavera Silenciosa", ao discorrer sobre o uso indiscriminado e imprudente de inseticidas químicos, faz referência à Declaração de Direitos do Homem e do Cidadão de 1789:

Não é minha afirmativa a de que os inseticidas químicos não devam ser usados nunca. Afirmo, não obstante, que pusemos, indiscriminadamente, substâncias químicas venenosas, biologicamente potentes, nas mãos de pessoas de todo ignorantes, ou quase, quanto à capacidade que tais substâncias têm, de produzir danos. Submetemos quantidades enormes de gente ao contato de venenos, sem o consentimento dessa gente, e, com frequência, também sem seu consentimento. Se a Declaração de Direitos não contém garantia alguma, que afirme que o cidadão deve ser protegido contra os venenos letais, distribuídos seja por indivíduos particulares, seja por funcionários públicos, isso se dá, por certo, apenas porque os nossos antepassados, a despeito de sua considerável sabedoria e do seu notável descortino, não poderiam conceber o aparecimento de semelhante problema. (2010, p. 28).

O princípio da dignidade da pessoa humana assume, portanto, um novo viés quando o assunto é a sociedade de risco e os danos ambientais. Temas como informação, conhecimento e consentimento passam a ganhar relevância e espectro político, notadamente quando a temática se consubstancia em danos à saúde corporal e mental do ser humano acarretados pela geração de riscos provenientes da produção de riquezas.

\section{O VAZIO ÉTICO: RUMO A UMA NOVA ÉTICA}


DOI 10.20873/uft.2359-0106.2021.v8n2.p86-115

Alguns autores, como Zygmunt Bauman e Jacques Ellul, identificam um vazio ético na pós-modernidade. Bauman estatui que a modernidade foi um processo de "derretimento dos sólidos"; ou seja, um processo de liquefação de tudo aquilo que persistisse no tempo e que fosse um obstáculo à sua passagem, com a finalidade única de construir novos e aperfeiçoados sólidos (2001, p. 9), conforme explicitado pelo autor no seguinte excerto:

Essa intenção clamava, por sua vez, pela "profanação do sagrado": pelo repúdio e destronamento do passado, e, antes e acima de tudo, da "tradição" isto é, o sedimento ou resíduo do passado no presente; clamava pelo esmagamento da armadura protetora forjada de crenças e lealdades que permitiam que os sólidos resistissem à "liquefação". Lembremos, no entanto, que tudo isso seria feito não para acabar de uma vez por todas com os sólidos e construir um admirável mundo novo livre deles para sempre, mas para limpar a área para novos e aperfeiçoados sólidos [...]. (BAUMAN, 2001, p. 9).

O papel destes "novos sólidos" era tornar o mundo previsível e seguro. Os primeiros "sólidos" a serem "derretidos" correspondiam às lealdades tradicionais, aos direitos costumeiros, aos deveres para com a família, bem como às obrigações éticas clássicas. Neste sentido:

O derretimento dos sólidos levou à progressiva libertação da economia de seus tradicionais embaraços políticos, éticos e culturais. Sedimentou uma nova ordem, definida principalmente em termos econômicos. Essa nova ordem deveria ser mais "sólida" que as ordens que substituía, porque, diferentemente delas, era imune a desafios por qualquer ação que fosse econômica. (BAUMAN, 2001, p. 10).

Bauman avalia que o contexto atual surgiu desta desregulamentação, liberalização ou "fluidez" (descontrole do mercado financeiro, imobiliário e do trabalho), e que hoje o mundo vive a era "pós-panóptica". No panóptico, o domínio do tempo era a fórmula do poder dos administradores e "imobilizar os subordinados no espaço, negando-Ihes o direito ao movimento e rotinizando o ritmo a que deviam obedecer era a principal estratégia em seu exercício do poder." (BAUMAN, 2001, p. 17).

Nesta concepção, o panóptico exigia dos detentores do poder que se fizessem presentes; exigia, outrossim, determinado engajamento e presença, características estas perdidas na sociedade "pós-panóptica". Assim, 
[...] as principais técnicas do poder são agora a fuga, a astúcia, o desvio e a evitação, a efetiva rejeição de qualquer confinamento territorial, com os complicados corolários de construção e manutenção da ordem, e com a responsabilidade pelas consequências de tudo, bem como a necessidade de arcar com os custos. (BAUMAN, 2001, p. 18).

Bauman entende que o ser humano vive em um mundo desprovido de ética - e não de uma ética específica, mas de toda e qualquer ética; ele identifica que houve uma emancipação, uma liberação dos "meios" com relação aos "fins": "se alguma coisa pode ser feita, deve ser e será feita. São os meios que justificam os fins - quaisquer fins que os meios podem produzir", uma vez que "os resultados são valiosos porque existe o know-how" (1997, p. 215).

Citando Max Weber, Bauman traz a ideia de que o mundo tratado pela tecnologia é um mundo desencantado, porquanto, sem propósito, intenção ou destino. Desta feita, a intenção é sempre futura e nunca um "projeto" a ser trabalhado no presente (BAUMAN, 1997, p. 221).

Jacques Ellul também explicita que, na civilização moderna, os meios são mais importantes que os fins, na mesma medida em que define técnica como um meio que é, concomitantemente, fim em si mesmo. A aplicação da técnica tornou-se inquestionável: aplica-se a técnica porque é possível aplicar a técnica e não porque há um objetivo a ser atingido. Exemplificando, os inseticidas são usados porque podem ser usados e não porque esta seja a melhor forma de combater-se as pragas que assolam as plantações:

A técnica tornou-se autônoma, e constitui um mundo devorador que obedece às suas próprias leis, renegando toda tradição. A técnica não mais repousa em uma tradição, mas na combinação de processos técnicos anteriores e sua evolução é rápida demais, por demais subversiva para integrar as tradições. (ELLUL, 1968, p. 13).

Bauman e Jacques Ellul observam um mundo em que não existe um objetivo a ser perquirido, em que não há uma ética que direcione vontades e comportamentos. É precisamente por causa deste cenário de vazio ético que Hans Jonas infere que a ética 
DOI 10.20873/uft.2359-0106.2021.v8n2.p86-115

antropocêntrica, que outrora era tida como paradigma, não mais atende todas as demandas da pós-modernidade:

É nesse vácuo, que simultaneamente também é o vácuo do relativismo de valores atual, que a presente pesquisa assume posição. $O$ que pode servir como bússola? A previsão do perigo. Antes de tudo nos seus relâmpagos surdos e distantes, vindos do futuro, na manifestação de sua abrangência planetária e na profundidade de seu comprometimento humano podem revelarse os princípios éticos dos quais se permitem deduzir as novas obrigações do novo poder. Eu denomino isso "heurística do medo": somente então, com a antevisão da desfiguração do homem, chegamos ao conceito de homem a ser preservado. Só sabemos o que está em jogo quando sabemos que está em jogo. Como se trata não apenas do destino do homem, mas também da imagem do homem, não apenas de sobrevivência física, mas também da integridade de sua essência, a ética que deve preservar ambas precisa ir além da sagacidade e tornar-se uma ética do respeito. (JONAS, 2007, p. 21).

A ética atém-se às consequências das ações humanas; entretanto, o agir humano atual, diferentemente do agir humano no passado, tem o poder de impactar o futuro de forma imprevisível e irreversível graças à denominada "técnica moderna". Neste prisma, se o âmbito de consequências das ações humanas foi alterado, os pressupostos éticos também passam a sofrer uma alteração. (JONAS, 2007, p. 29).

A designada "técnica moderna" permitiu que a natureza se tornasse objeto da responsabilidade humana. Anteriormente, a natureza "cuidava de si mesma e, com a persuasão e a insistência necessárias, também tomava conta do homem: diante dela eram úteis a inteligência e a inventividade, não a ética". Atualmente, porém, o ser humano detém poder sobre a natureza e, justamente por este motivo, passou a ser detentor de uma responsabilidade diferente. A natureza tornou-se vulnerável diante das intervenções técnicas da humanidade:

Por meio de seus efeitos, ela nos revela que a natureza da ação humana foi modificada de facto, e que um objeto de ordem inteiramente nova, nada menos do que a biosfera inteira do planeta, acresceu-se àquilo pelo qual temos de ser responsáveis, pois sobre ela detemos poder. Um objeto de uma magnitude tão impressionante, diante da qual todos os antigos objetos da ação humana parecem minúsculos! A natureza como uma responsabilidade humana é seguramente um novum sobre o qual uma nova teoria ética deve ser pensada. 
DOI 10.20873/uft.2359-0106.2021.v8n2.p86-115

Que tipo de deveres ela exigirá? Haverá algo mais do que o interesse utilitário? [...] (JONAS, 2007, p. 39).

A ética - ao menos até o momento presente - era antropocêntrica, dado que sua significação era centrada no relacionamento do homem consigo mesmo e com os demais. A essência humana não era objeto da técnica, mas sim uma constante compreendida como condição fundamental (mesmo porque as ações humanas tinham somente um alcance imediato, dispensando-se qualquer planejamento a longo prazo).

Ademais, o domínio da técnica era, com exceção da medicina, eticamente neutro, tanto sob o ponto de vista do sujeito, visto que a técnica era determinada pela necessidade, quanto sob o ponto de vista do objeto, porquanto este somente era afetado de maneira superficial. (JONAS, 2007, p. 35):

Todos os mandamentos e máximas da ética tradicional, fossem quais fossem suas diferenças de conteúdo, demonstram esse confinamento ao círculo imediato da ação. "Ama o teu próximo como a ti mesmo"; "faze aos outros o que gostarias que eles fizessem a ti"; "Instrui teu filho no caminho da verdade" [...] Em todas essas máximas, aquele que age e o "outro" de seu agir são partícipes de um presente comum. [...] O universo moral consiste nos contemporâneos, e o seu horizonte futuro limita-se à extensão previsível do tempo de suas vidas. (JONAS, 2007, p. 36).

Hans Jonas assinala que as delimitações de proximidade e simultaneidade, acima traçadas, foram rompidas pelo crescimento espacial e pelo prolongamento temporal das sequências de causa e efeito, "postas em movimento pela práxis técnica mesmo quando empreendidas para fins próximos". (2007, p. 40):

Até aqui demonstramos a pertinência das pressuposições: o nosso agir coletivo-cumulativo-tecnológico é de um tipo novo, tanto no que se refere aos objetos quanto à sua magnitude. Por seus efeitos, independentemente de quaisquer intenções diretas, ele deixou de ser eticamente neutro. Com isso se inicia a tarefa propriamente dita, a de buscar uma resposta. (2007, p. 66).

O dever de conhecer, de saber, tornou-se prioritário, porque o "hiato entre a força da previsão e o poder do agir produz um novo problema ético" (JONAS, 2007, p. 41): as consequências das ações humanas tornaram-se imprevisíveis e, mediante o avanço da 
técnica, passaram a protrair-se no tempo e no espaço de forma cumulativa, em virtude da somatória de seus efeitos.

Entretanto, o ser humano ainda não conhece a magnitude dessas consequências; portanto, "reconhecer a ignorância torna-se, então, o outro lado da obrigação do saber, e com isso torna-se uma parte da ética que deve instruir 0 autocontrole". (JONAS, 2007, p. 41).

Immanuel Kant, ao buscar o fundamento filosófico dos direitos e dos deveres, baseia-se na noção de que os seres humanos são racionais e, portanto, detentores de dignidade e respeito. A moral, para Kant, está "fundamentada no respeito às pessoas como fins em si mesmas." (SANDEL, 2012, p. 139).

Kant não admitia que os princípios morais fossem baseados em preferências ou desejos, porque essa distinção não teria qualquer serventia na diferenciação do que é certo ou errado. Com efeito, Kant traz a noção de que as pessoas poderiam alcançar o princípio supremo da moralidade por meio do exercício da "pura razão prática" (SANDEL, 2012, p. 139).

Segundo Kant, o ser humano teria a capacidade de raciocinar e de determinar o seu comportamento conforme a sua razão, o que não significa dizer que uma pessoa sempre - e em todas as situações - age de acordo com a razão, mas sim que "a razão pode ser soberana, pelo menos parte do tempo. Quando a razão comanda nossa vontade, não somos levados apenas pelo desejo de procurar o prazer e evitar a dor" (SANDEL, 2012, p. 140).

Para Kant, agir livremente significa "agir com autonomia": o indivíduo só seria livre se agisse de acordo com uma lei interna, que ele próprio se impôs. Assim, o ser humano não age com liberdade quando as suas condutas são determinadas por fatores externos, como convenções sociais ou impulsos naturais (SANDEL, 2012, p. 141):

Quando agimos com autonomia e obedecemos a uma lei que estabelecemos para nós mesmos, estamos fazendo algo por fazer algo, como uma finalidade em si mesma. Deixamos de ser instrumentos de desígnios externos. Essa capacidade de agir com autonomia é o que confere à vida humana sua dignidade especial. Ela estabelece a diferença entre pessoas e coisas. (2012, p. 142/143). 
DOI 10.20873/uft.2359-0106.2021.v8n2.p86-115

A princípio, para Kant, o que seria capaz de conferir valor moral a uma ação seria o dever. Desta feita, uma ação só teria valor moral acaso tivesse sido praticada por causa do dever e não em virtude de interesses próprios ou de terceiros, independentemente de suas consequências. Kant está "observando que, quando avaliamos o valor moral de uma ação, estamos avaliando o motivo pelo qual ela é praticada, e não suas consequências." (SANDEL, 2012, p. 144).

É com base nesta ideia de liberdade que Kant traça a diferença entre imperativos hipotéticos e imperativos categóricos. Os imperativos hipotéticos seriam sempre condicionais, assim, neste caso, restaria demonstrado que uma ação somente é boa como um meio para que algo seja atingido ("se você deseja X, então faça Y"); de outro lado, o imperativo categórico seria incondicional, hipótese em que a ação é boa por si mesmo, de sorte que se estaria diante de um imperativo da moralidade. (SANDEL, 2012, p. 151).

Ainda sob a ótica dos imperativos categóricos, Kant acredita que somente "devemos agir de acordo com os princípios que podemos universalizar sem entrar em contradição". (SANDEL, 2012, p. 152).

Ato contínuo, Kant explicita que a lei moral não pode estar fundamentada em interesses ou objetivos particulares, de forma que se deve perquirir algo que apresente valor em si mesmo. No caso, Kant entende que a humanidade compreende um fim em si mesmo, um valor absoluto (SANDEL, 2012, p. 154):

Essa linha de raciocínio conduz Kant à segunda formulação do imperativo categórico: "Aja de forma a tratar a humanidade, seja na sua pessoa, seja na pessoa de outrem, nunca como um simples meio, mas sempre ao mesmo tempo como um fim." Essa é a concepção da humanidade como um fim em si mesma. (SANDEL, 2012, p. 154).

Hans Jonas bem observa que os imperativos categóricos de Kant são voltados para o indivíduo, valendo-se de um critério momentâneo. Jonas explica que novos 
DOI 10.20873/uft.2359-0106.2021.v8n2.p86-115

imperativos devem ser formulados em virtude da mudança que ocorreu no âmbito de consequências do agir humano:

Um imperativo adequado ao novo tipo de agir humano e voltado para o novo tipo de sujeito atuante deveria ser mais ou menos assim: "Aja de modo a que os efeitos da tua ação sejam compatíveis com a permanência de uma autêntica vida humana sobre a Terra"; ou, expresso negativamente: "Aja de modo a que os efeitos da tua ação não sejam destrutivos para a possibilidade futura de uma tal vida"; ou, simplesmente: "Não ponha em perigo as condições necessárias para a conservação indefinida da humanidade sobre a Terra"; ou, em uso novamente positivo: "Inclua na tua escolha presente a futura integridade do homem como um dos objetos do teu querer." (2007, p. 47/48).

Os fundamentos desta nova ética, segundo Hans Jonas, podem ser encontrados na heurística do medo; o ser humano desconhece as consequências de suas ações, na medida em que o "saber exigido sempre é, necessariamente, um saber ainda não disponível no momento e jamais disponível como conhecimento prévio." (JONAS, 2007, p. 73).

Nesta perspectiva, como desconhece os perigos de suas ações, também desconhece o que deve ser protegido e o porquê deve ser protegido, "por isso, contrariando toda lógica e método, o saber se origina daquilo contra o que devemos nos proteger." (JONAS, 2007, p. 71). Entretanto, o desconhecimento retro mencionado não impede que sejam formulados prognósticos com base em possibilidades ou projeções. Jonas acredita que o mau prognóstico deve sobrepor-se ao bom prognóstico, porque não seria aconselhável arriscar irreversivelmente toda a humanidade (JONAS, 2007, p. 77):

Partimos do fato de que a incerteza dos prognósticos de longo prazo, em um contexto em que o equilíbrio entre as alternativas paralisa a utilização dos princípios na esfera dos fatos, deve ser considerada, por sua vez, um fato. Para lidar com ele corretamente, a ética deve dispor de um princípio que não seja ele próprio também incerto. $O$ que explicamos até agora foi a prescrição prática no qual o princípio se expressa: a de que, em assuntos de certa magnitude aqueles com potencial apocalíptico, - deve-se dar mais peso ao prognóstico do desastre do que ao prognóstico da felicidade. (2007, p. 83). 
O princípio ético fundamental, segundo Hans Jonas, é o de que a "existência ou a essência do homem, em sua totalidade, nunca podem ser transformadas em apostas do agir." (2007, p. 86). O mero prognóstico de ameaça à existência ou essência humanas é suficiente para que o risco eventualmente analisado seja taxado como inaceitável. Todo raciocínio ético construído até o presente momento estriba-se na reciprocidade entre direitos e deveres; contudo, a ideia de reciprocidade não serve mais para amparar a nova ética.

O arquétipo do agir responsável passa a ser encontrado na responsabilidade que os pais têm para com os filhos, dado que os cuidados e atenções dispendidas são, a priori, unilaterais, ainda que se espere um retorno no futuro. Há, assim, um dever para com a existência da humanidade futura, bem como um dever com relação à sua condição:

Esse é então o primeiro dever para com o modo de ser dos descendentes, que só pode ser deduzido do dever de fazê-los existir. Desse dever decorrem também os outros deveres para com eles, como, por exemplo, o dever para com as suas possibilidades de felicidade. (JONAS, 2007, p. 93).

Em uma última análise, a ética preconizada por Hans Jonas é uma ética da responsabilidade, com um viés cumulativo, porquanto não se trata de garantir um direito, mas sim um dever das futuras gerações, qual seja, o dever de continuar existindo. As fundamentações filosófica e metafísica do porquê a humanidade tem o dever de existir não são objetos deste artigo.

Outrossim, o que se busca evidenciar é que o princípio da dignidade da pessoa humana não pode mais ser analisado somente através da ética clássica ou dos ideais kantianos, em que o indivíduo é visto como fim em si mesmo: a pós-modernidade exige a presença de uma nova ética capaz de garantir a existência e a dignidade das presentes e das futuras gerações.

\section{SOBRE O DIREITO À EDUCAÇÃO PARA VIVER O RISCO}


Em primeiro plano, compreende-se uma ligação evidente e até mesmo inevitável entre a conscientização sobre a "sociedade de risco" e a educação científica, firmada sobre os aspectos de preservação ambiental e de sustentabilidade. Desta forma, a construção deste conhecimento no ensino fundamental e médio já seria possível majoritariamente dentro do currículo das ciências naturais. Estaria estabelecida assim uma justificativa pragmática e um recorte disciplinar para que se possa estudar a noção de risco na sociedade contemporânea. Contudo, ao ser preconizada pela Declaração dos Direitos Humanos de 1948 e pela Constituição Federal de 1988, à educação, de maneira geral, estão atreladas características essenciais para a vida em uma sociedade democrática: "fortalecimento do respeito pelos direitos do ser humano" (1948); "preparo para o exercício da cidadania" (1988).

O desenvolvimento tecnológico apresenta um papel dúbio. Por um lado, traz a produção de riquezas, tentativa de oferecer maior segurança e possibilitar novas e melhores soluções aos envolvidos em um determinado contexto. Por outro lado, traz a potencialização de riscos, gera efeitos colaterais muitas vezes desconhecidos, não só locais, mas globais: poluição, aquecimento global e contaminações são alguns exemplos. Por isso, ao pensar em ameaças planetárias, o respeito pelos direitos humanos e o preparo para exercer a cidadania tornam-se ainda mais abrangentes.

A ênfase na interdisciplinaridade da análise das questões ambientais deve-se à
constatação de que os problemas que afetam e mantêm a vida no nosso
planeta são de natureza global e que suas causas não podem restringir-se
apenas aos fatores estritamente biológicos, revelando dimensões políticas,
econômicas, institucionais, sociais e culturais. (JACOBI, 2007, p.60)

Sendo assim, isolamentos ideológicos e restrições às mais variadas produções de conhecimento não combinam com o enfrentamento dos riscos, ao contrário, podem agravá-los. A estratégia de negar ou silenciar sobre ameaças não as extingue. $\mathrm{Na}$ modernidade tardia, a lógica é simples, como aponta Beck (2010, p.32) “(...) ameaças são um subproduto modernizacional de uma abundância a ser evitada. Cabe ou 
erradica-la ou então negá-la, reinterpretando-a". Obtidas no mesmo processo, diferentemente, as riquezas sociais são cobiçadas, disputadas e tendem a se tornar posse de poucos.

Ao propor uma "interpretação programática" sobre o direito à educação, José Sérgio Fonseca de Carvalho (2018), estabelece a condição ímpar deste direito social diante de outros também classificados assim. É um direito que aspira à universalidade sem ser muito contestado a princípio. De fato, políticas públicas, iniciativas do terceiro setor, debates acadêmicos e conversas informais parecem convergir para a necessidade inquestionável de que às crianças e adolescentes não podem ser negadas oportunidades de estudar ou "acessar e permanecer na escola" de algum modo.

Por outro ponto de vista, assim como outros de seus congêneres, a forma de efetivação deste direito não é consenso. Controvérsias acumulam-se: como deve organizar-se a instituição escolar? Deve existir uma instituição escolar? Pública? Privada? É necessário frequentá-la regularmente? Qual seria o currículo adequado? Por que seria adequado? Se a escola apenas reproduz violências e desigualdades, para quem e para que ela serve? Se é um espaço de ressignificação e constantes experiências transformadoras, como quantificar seus resultados? Quais são os melhores resultados escolares? Estas e diversas outras questões poderiam ser formuladas e receber as mais variadas respostas, dependendo do viés de análise.

Não é objetivo deste artigo defender ou se aprofundar neste ou naquele viés. No entanto, em paralelo, destaca-se a pergunta central formulada por Carvalho e o seu importante direcionamento de olhar para se pensar o direito à educação. Seu foco, "além e aquém" das discussões jurídicas, das pesquisas acadêmicas e das propostas de políticas públicas traz consigo um tipo de interpretação do que poderia significar este direito para a dignidade da pessoa humana na pós-modernidade.

Trata-se de interrogar aquilo que permanece obscuro - ou ao menos tácito nas investigações acerca de seus meios de efetivação. O que aqui se pretende levar a cabo é, pois, uma interrogação acerca da própria natureza desse bem jurídico - o direito à educação - cujos meios de viabilização e efetividade têm sido objeto de inúmeras investigações, análises e proposições de políticas 
públicas. A pergunta que nos move - ao que alguém tem direito quando reconhecemos seu direito à educação? (CARVALHO, 2018, p.1)

Este grande questionamento, que não é ocioso e sem propósito, pode ser facilmente respondido do ponto de vista legal e possui explicações sociológicas e históricas. Entretanto, quando são retomadas as noções de interconexão entre gerações e a própria continuidade da existência humana, a pergunta promove a reflexão sobre qual tipo de relação a sociedade deseja manter com a educação. Uma relação instrumental, calcada objetivamente em meios e fins pode ser uma resposta, mas não é a única.

Diferentes grupos disputam a melhor afirmação em resposta à questão "para que serve a educação?". Possíveis respostas seriam: conseguir aprovação no vestibular, preparar-se para o trabalho, formar cidadãos críticos às iniquidades sociais, impulsionar o empreendedorismo, treinar comportamentos adequados à vida em sociedade, tornarse um consumidor consciente.

Alguns grupos exigem que a educação seja um simples meio para alcançar um fim específico e, tal qual uma indústria, a escola geraria produtos finais que deverão inserir-se na ordem social vigente sem questionar seu padrão de funcionamento, preocupações ou prioridades.

A competência se mede, portanto, pela eficácia dos resultados. Mas o mesmo não vale para o cultivo de um princípio ético. Pode-se dizer que alguém é um "orador competente", mas usa sua competência para o "mal", embora não tenha sentido afirmar que alguém é "justo" para o mal, pois seria injusto. Assim, a ação educativa de "qualidade" é, nessa perspectiva, essencialmente de natureza política e ética, e sua plena efetivação não resulta apenas do desenvolvimento de "competências" ou "capacidades", mas do lento cultivo de um modo de vida ao qual se atribui valor absoluto e não relativo. (CARVALHO, 2018, p.4).

A efetivação ou não do direito à educação tem repercussões coletivas. Espera-se que as pessoas vivenciem esta transição do âmbito familiar para a vida pública. $\mathrm{Na}$ esfera jurídica, caso não seja ofertado ou seja oferecido de forma irregular, causará responsabilização das autoridades competentes e/ou da família. No âmbito existencial, interpretado aqui, é importante ressaltar que o direito à educação não separa meios e 
DOI 10.20873/uft.2359-0106.2021.v8n2.p86-115

fins. Não serão formados leitores sem que se tenha apreço à leitura, nem escritores, sem que sejam valorizadas as produções escritas dos estudantes, assim como, não será possível conscientizar sobre os riscos globais sem que exista o princípio da empatia diante da pluralidade do mundo.

A educação é o ponto em que decidimos se amamos o mundo o bastante para assumirmos a responsabilidade por ele e, com tal gesto, salvá-lo da ruína que seria inevitável não fossem a renovação e a vinda dos novos e dos jovens. A educação é também onde decidimos se amamos nossas crianças o bastante para não expulsá-las de nosso mundo e abandoná-las a seus próprios recursos, e tampouco arrancar de suas mãos a oportunidade de empreender alguma coisa nova e imprevista para nós, preparando-as, em vez disso, com antecedência para a tarefa de renovar um mundo comum. (ARENDT, 2010, p.247).

Partindo do pressuposto de que a raça humana deva continuar existindo, a educação para viver em uma sociedade de risco exige cuidado com o mundo e, em concomitância, com sua diversidade.

Entrever um modo de vida que assume responsabilidades com base em princípios éticos amplos provavelmente significa buscar um ideal que não será alcançado. Contudo, advindas do mesmo processo, a geração de riscos e riquezas é inerente ao modo de vida atual, ou seja, uma constante para a qual não equivalem ações fortuitas. Cuidar do mundo e dialogar com o passado, o presente e o futuro não são tarefas de disciplinas escolares isoladas.

\section{O PRINCÍPIO DA DIGNIDADE DA PESSOA HUMANA: DESAFIOS À LUZ DA SOCIEDADE DE RISCO}

Norberto Bobbio, na obra intitulada "A era dos Direitos", comenta que o grande problema da atualidade não é mais o de fundamentar direitos, mas sim o de conferir proteção e efetividade aos denominados direitos humanos. A questão concernente à 
DOI 10.20873/uft.2359-0106.2021.v8n2.p86-115

proteção e à efetividade dos direitos humanos perpassa não só pela esfera jurídica, mas também pelo âmbito político. (2004, p. 17).

$\mathrm{Na}$ sociedade de risco, a garantia da dignidade da pessoa humana não é um desafio que pertence somente ao universo jurídico. Sob o espectro factual, a dignidade da pessoa humana é ameaçada pela imprevisibilidade das consequências das ações humanas. A título exemplificativo, cita-se o rompimento da barragem no município de Brumadinho, em 25 de janeiro de 2019. O rompimento da barragem, além de ter causado óbvios impactos sociais imediatos, também causou danos ambientais, cujas repercussões serão sentidas por gerações futuras.

Neste passo, a garantia efetiva da dignidade da pessoa humana, em um mundo no qual os danos extrapolam o espaço e o tempo próximos, inclusive de forma irreversível, deve ser objeto de preocupação não só do Direito, mas também de outras disciplinas. Com efeito, a ética, por sua vez, deve assumir um novo viés (cumulativo e pautado na responsabilidade), nos termos apontados anteriormente. Bobbio explica que os direitos humanos "nascem como direitos naturais universais, desenvolvem-se como direitos positivos particulares, para finalmente encontrarem sua plena realização como direitos positivos universais". (2004, p. 19). É, neste sentido, que o autor afirma o seguinte:

Com a Declaração de 1948, tem início uma terceira e última fase, na qual a afirmação dos direitos é, ao mesmo tempo, universal e positiva: universal no sentido de que os destinatários dos princípios nela contidos não são mais apenas cidadãos deste ou daquele Estado, mas todos os homens; positiva no sentido de que põe em movimento um processo em cujo final os direitos do homem deverão ser não mais apenas proclamados ou apenas idealmente reconhecidos, porém efetivamente protegidos até mesmo contra o próprio Estado que os tenha violado. No final desse processo, os direitos do cidadão terão se transformado, realmente, positivamente, em direitos do homem. (BOBBIO, 2004, p. 19).

A necessidade premente de uma constante atualização e reformulação desses direitos, dado que eles assumem uma perspectiva histórica inquestionável, é proveniente dos desenvolvimentos da técnica e das novas condições sociais e 
DOI 10.20873/uft.2359-0106.2021.v8n2.p86-115

econômicas. (BOBBIO, 2004, p. 20). Portanto, os direitos encartados na Declaração de 1948 devem ser constantemente especificados e revistos. A reformulação das condições sociais, políticas e econômicas permite que se realize uma referência, por exemplo, ao direito de participar do poder econômico e de não ser alvo de propaganda enganosa ou de notícias falsas:

[...] a necessidade de não se ser enganado, excitado ou perturbado por uma propaganda maciça e deformadora; começa a se esboçar, contra o direito de expressar as próprias opiniões, o direito à verdade das informações. No campo do direito à participação no poder, faz-se sentir na medida em que o poder econômico se torna cada vez mais determinante nas decisões políticas e cada vez mais decisivo nas escolhas que condicionam a vida de cada homem - a exigência de participação no poder econômico ao lado e para além do direito (já por toda parte reconhecido, ainda que nem sempre aplicado) de participação no poder político. (BOBBIO, 2004, p. 20).

Em vista disso, é necessário que haja uma proteção internacional efetiva dos direitos humanos; entretanto, os organismos internacionais aplicam, em relação aos Estados, uma vis directiva (e não coativa), a qual, para que alcance a sua finalidade, depende da existência de uma autoridade capaz de incutir o respeito ou o temor reverencial e de uma receptividade ou disposição daquele sobre o qual é exercido o poder. (BOBBIO, 2004, p. 22).

A tutela dos direitos humanos é feita pelos organismos internacionais por meio da promoção, do controle e da garantia. Conforme aponta Norberto Bobbio, o objetivo da promoção é induzir os Estados que já têm um sistema de proteção de direitos a aperfeiçoá-los e, de outro lado, induzir os Estados que não possuem esse sistema a implementá-lo. (BOBBIO, 2004, p. 23).

O controle, por sua vez, é feito por meio das medidas implementadas por organismos internacionais, a fim de avaliar se as suas recomendações são acolhidas ou se as suas convenções são observadas. Por fim, a garantia dos direitos da pessoa humana, no plano internacional, consubstancia-se na presença de uma tutela jurisdicional internacional, como é o caso de a possibilidade de demandas individuais serem encaminhadas à Comissão Europeia dos Direitos do Homem. 
DOI 10.20873/uft.2359-0106.2021.v8n2.p86-115

Bobbio assevera que somente se poderá discursar sobre uma tutela internacional efetiva dos direitos humanos quando a jurisdição internacional lograr impor-se e superpor-se às jurisdições nacionais. (BOBBIO, 2004, p. 23):

Deve-se recordar que a luta pela afirmação dos direitos do homem no interior de cada Estado foi acompanhada pela instauração dos regimes representativos, ou seja, pela dissolução dos Estados de poder concentrado. Embora toda analogia histórica deva ser feita com muita cautela, é provável que a luta pela afirmação dos direitos do homem também contra o Estado pressuponha uma mudança que, de fato, já está em andamento, ainda que lento, sobre a concepção do poder externo do Estado em relação aos outros Estados, bem como um aumento do caráter representativo dos organismos internacionais. (BOBBIO, 2004, p. 23).

A proteção efetiva destes direitos também encontra dificuldades atinentes aos seus próprios conteúdos, porquanto a maioria dos direitos fundamentais não é absoluta, mas sim relativa. Assim, o conflito entre os direitos fundamentais relativos é resolvido, na opinião de Norberto Bobbio, de acordo com critérios vagos (valorativos), o que representaria um obstáculo ao princípio da certeza que deveria nortear as relações jurídicas (BOBBIO, 2004, p. 24):

Esclareço dizendo que chamo de "liberdades" os direitos que são garantidos quando o Estado não intervém; e de "poderes" os direitos que exigem uma intervenção do Estado para sua efetivação. Pois bem: liberdades e poderes, com frequência, não são - como se crê - complementares, mas incompatíveis. Para dar um exemplo banal, o aumento do poder de comprar automóveis diminuiu, até quase paralisar, a liberdade de circulação. (BOBBIO, 2004, p. 24/25).

Questiona-se: como é possível referir-se à segurança jurídica no mundo do Direito se não é mais possível falar em segurança no mundo dos fatos? Se o ser humano não pode mais prever as consequências de suas ações, cujo espectro ultrapassa as noções usuais de espaço e de tempo, como poderia prever juridicamente as respostas que o Direito deveria conferir a essas consequências? Como poderia construir critérios racionais para a resolução do conflito entre os direitos fundamentais relativos? 
No que tange ao conflito entre dois ou mais direitos fundamentais relativos, o neoconstitucionalismo traz uma proposta de resolução. Em apertada síntese, é possível inferir que o neoconstitucionalismo abarca três teses, quais sejam: a vinculação entre o Direito e a Moral, a divisão entre as regras e os princípios e a aplicação do Direito por ponderação.

Com efeito, para Alexy, os princípios nada mais são do que valores positivados que a Constituição teria estabelecido ao elencar direitos fundamentais, uma ordem objetiva de valores.

O neoconstitucionalismo traz a possibilidade de que uma norma válida no plano abstrato deixe de ser aplicada quando as razões específicas do caso concreto justificarem o seu afastamento; entretanto, o neoconstitucionalismo, apesar de conceder ao agente um âmbito decisório mais alargado, em que se faculta a este agente fazer escolhas, também traz a ideia de que o agente não está autorizado a fazer qualquer escolha: o agente deve fazer a escolha que esteja em maior conformidade com os valores constitucionais explícitos ou implícitos. Assim, o neoconstitucionalismo aproxima o Direito da Moral, mas não de qualquer moral ou valor.

Bobbio explica que uma discussão sobre os direitos humanos deve levar em conta "todas as dificuldades procedimentais e substantivas" e que a "efetivação de uma maior proteção dos direitos do homem está ligada ao desenvolvimento global da civilização humana". (2004, p. 25).

Assim, a abordagem do problema deve dar-se de maneira transdisciplinar. A efetivação dos direitos humanos - imperativa para a concretização do princípio da dignidade da pessoa humana - deve ser analisada não somente por intermédio do Direito, mas também por meio de outras disciplinas (Economia, Psicologia, Política, Antropologia, Sociologia, Filosofia e História).

O paradigma simplificador, conforme explica Edgar Morin, expulsa do universo qualquer espécie de desordem. "A ordem se reduz a uma lei, a um princípio. A simplicidade vê o uno, ou o múltiplo, mas não consegue ver que o uno pode ser ao mesmo tempo múltiplo." (2005, p. 59): 
DOI 10.20873/uft.2359-0106.2021.v8n2.p86-115

Tomemos o homem como exemplo. O homem é um ser evidentemente biológico. É ao mesmo tempo um ser evidentemente cultural, metabiológico e que vive num universo de linguagem, de ideias e de consciência. Ora, estas duas realidades, a realidade biológica e a realidade cultural, o paradigma da simplificação nos obriga a disjuntá-las ou a reduzir o mais complexo ao menos complexo. Vamos, pois, estudar o homem biológico no departamento de biologia, como um ser anatômico, fisiológico, etc. e vamos estudar a mente, the mind, como função ou realidade psicológica. Esquecemos que um não existe sem a outra, ainda mais que um é a outra ao mesmo tempo, embora sejam tratados por termos e conceitos diferentes. (MORIN, 2005, p. 59).

Em contraposição ao paradigma da simplificação, surge o pensamento complexo ou, ainda, o paradigma da complexidade erigido por Morin, cuja sugestão é o desenvolvimento da percepção de um conhecimento multidimensional. O conhecimento multidimensional revela $o$ quão estreito é o conhecimento unidimensional ou meramente especializado:

A visão não complexa das ciências humanas, das ciências sociais, considera que há uma realidade econômica de um lado, uma realidade psicológica de outro, uma realidade demográfica de outro, etc. Acredita-se que estas categorias criadas pelas universidades sejam realidades, mas esquece-se que no econômico, por exemplo, há as necessidades e os desejos humanos. Atrás do dinheiro, há todo um mundo de paixões, há a psicologia humana. (2005, p. 68).

A incerteza, para Morin, não pode ser expurgada do conhecimento. É a presença da desordem e das anomalias que permite o constante avanço e aperfeiçoamento do saber. Ademais, a visão unidimensional ou parcelar dos problemas surgidos na pósmodernidade é uma visão frustrada, porquanto impotente diante das incertezas e da desordem que são próprias desta nova configuração social.

O princípio disjuntivo surgido com o paradigma idealizado por Descartes "separou de um lado o campo do sujeito, reservado à filosofia, à meditação interior, de outro lado o campo do objeto em sua extensão, campo do conhecimento científico, da mensuração e da precisão." (MORIN, 2005, p. 76).

Por conseguinte, as anomalias com as quais os atuais paradigmas jurídicos não conseguem lidar são imprescindíveis para o avanço e o aperfeiçoamento da Ciência 
Jurídica; contudo, a solução da problemática não pode ser alcançada somente por intermédio do Direito, devendo existir um diálogo transdisciplinar com outras áreas do conhecimento.

A proteção efetiva dos direitos humanos, necessária para a garantia da dignidade da pessoa humana, no cenário traçado durante a elaboração deste artigo, não pode ser somente um objeto de atenção do Direito, mas também de outros campos de estudo (filosofia, psicologia, literatura, medicina, sociologia, etc.).

Neste sentido, o paradigma complexo "resultará do conjunto de novas concepções, de novas visões, de novas descobertas e de novas reflexões que vão se acordar, se reunir." (MORIN, 2005, p. 77). Entende-se, portanto, que uma visão unidimensional ou meramente especializada não é mais suficiente diante do cenário traçado ao longo deste artigo.

\section{CONSIDERAÇÕES FINAIS}

O presente artigo foi elaborado com o objetivo de analisar quais são os desafios que a efetivação do princípio da dignidade da pessoa humana enfrenta na sociedade de risco, bem como apontar possíveis soluções para a problemática. A pesquisa realizada teve o condão de apontar que a concretização do princípio da dignidade da pessoa humana defronta-se com as seguintes situações:

(a) Atualmente, a produção de riquezas na sociedade vem acompanhada da geração de riscos e, em que pese o fato de os riscos produzidos não obedecerem à lógica da sociedade de classes, os agentes que possuem melhores condições financeiras têm a possibilidade de protegerem-se de eventuais impactos negativos de forma mais efetiva;

(b) Os impactos ambientais causados pela produção de riquezas importam em prejuízo à biodiversidade e, por consequência, à vida humana, inclusive sob o enfoque psicológico;

(c) A ética, tradicionalmente antropocêntrica, não é mais capaz de responder a todos os problemas surgidos a partir da pós-modernidade; o 
âmbito consequencial do agir humano sofreu uma modificação causada pelo avanço da técnica moderna. Assim, o surgimento de um novo paradigma ético, mediante um viés cumulativo e pautado na responsabilidade, é imprescindível na pós-modernidade.

(d) O direito à educação, para viver em uma sociedade de risco, exige o cultivo do princípio ético explicado neste artigo.

(e) No âmbito internacional, ainda não há uma tutela dos direitos humanos, porquanto as jurisdições internacionais ainda não conseguem impor-se às jurisdições nacionais;

(f) $\quad \mathrm{O}$ conflito entre direitos fundamentais relativos é resolvido, na opinião de Bobbio, de acordo com critérios valorativos e, portanto, vagos;

(g) A efetivação dos direitos humanos perpassa por questões que não são somente jurídicas, mas também políticas e econômicas.

Com efeito, a pesquisa também trouxe eventuais soluções para as questões apresentadas. Assim, como a efetivação dos direitos humanos abrange questões que não são somente jurídicas, sugeriu-se uma abordagem transdisciplinar da problemática, sob a ótica do paradigma da complexidade de Edgar Morin, que abarca, na construção do conhecimento, a incerteza (característica da sociedade de risco).

Quanto à tutela jurídica destes direitos no âmbito internacional, é necessário que haja uma maior representatividade de todos os Estados nos organismos internacionais, bem como uma maior possibilidade de que os pleitos individuais sejam levados ao conhecimento de comissões internacionais.

No tocante ao conflito entre direitos fundamentais relativos, o neoconstitucionalismo aparece como alternativa à aparente inexistência de critérios concretos para a resolução da supracitada controvérsia; a teoria aproxima o Direito dos valores constitucionais, além de conferir integridade ao ordenamento jurídico.

Conclui-se, também, que eventuais pesquisas subsequentes podem analisar como será feita, na prática, a abordagem transdisciplinar retromencionada, inclusive na relação entre sociedade de risco e educação, bem como, perscrutar os critérios 
ISSN no 2359-0106

Vol. 8, n. 2, 2021.

DOI 10.20873/uft.2359-0106.2021.v8n2.p86-115

construídos pelo neoconstitucionalismo para resolver conflitos entre direitos fundamentais relativos, sem deixar de sugerir critérios aditivos a fim de aperfeiçoar a teoria existente.

\section{REFERÊNCIAS}

ALEXY, Robert. Teoria dos direitos fundamentais. São Paulo: Malheiros, 2011.

ARENDT, Hannah. A condição humana. Rio de Janeiro, Forense, 2010.

BARROSO, Luís Roberto. Fundamentos Teóricos e Filosóficos do Novo Direito Constitucional Brasileiro. Revista da Escola da Magistratura do Estado do Rio de Janeiro, EMERJ, Rio de Janeiro, v. 4, n.15, 2001.

BAUMAN, Zygmunt. Modernidade Líquida. São Paulo: Zahar, 2001.

BECK, Ulrich. Sociedade de Risco - rumo a uma outra modernidade. São Paulo: Editora 34, 2010.

BITTAR, Eduardo Carlos Bianca. O direito na pós-modernidade. Sequência: Estudos Jurídicos e Políticos. Florianópolis, n. 57, 2008.

BOBBIO, Norberto. A Era dos Direitos. Rio de Janeiro: Elsevier, 2004.

CARSON, Rachel. Primavera Silenciosa. São Paulo: Gaia, 2010.

CARVALHO, José Sérgio Fonseca de. Uma interpretação programática do direito à educação. Revista USP 119, Editora SCS/USP, São Paulo, outubro/novembro/dezembro, 2018.

ELLUL, Jacques. A Técnica e o Desafio do Século. Rio de Janeiro: Paz e terra, 1968.

JACOBI, Pedro Roberto. Educar na sociedade de risco: o desafio de construir alternativas. Pesquisa em Educação Ambiental. UNESP, v.2, n.2, p 49-65, 2007.

JONAS, Hans. O princípio da responsabilidade: ensaio de uma ética para a civilização tecnológica. Rio de Janeiro: Contraponto, 2007. 
DOI 10.20873/uft.2359-0106.2021.v8n2.p86-115

KUHN, Thomas. A estrutura das revoluções científicas. São Paulo: Perspectiva, 1998.

MORIN, Edgar. Introdução ao pensamento complexo. Porto Alegre: Sulina, 2005.

SANDEL, Michael. Justiça - o que é fazer a coisa certa. Rio de Janeiro: Civilização brasileira, 2012.

WILSON, Edward O. Diversidade da vida. São Paulo: Companhia das Letras, 2012. 